\title{
Expresión de genes del metabolismo de lípidos y colesterol en fibroblastos de pterigión: análisis comparativo con adipocitos y otros fibroblastos
}

\section{Lipid and cholesterol metabolism gene expression in pterygium fibroblasts: comparative analysis with adipocytes and other fibroblasts}

\author{
Judith Zavala*, Víctor Treviño, Arely A. Reyna-Fuentes, Clarissa M. Arellano-Gurrola, \\ Daniela Enriquez-Ochoa, Jorge L. Domene-Hickman y Jorge E. Valdez-García \\ Tecnológico de Monterrey, Escuela de Medicina y Ciencias de la Salud, Monterrey, México
}

\section{Resumen}

Propósito: Comparar el nivel de expresión génica asociada al metabolismo de lípidos y colesterol en fibroblastos de pterigión, adipocitos y otros tipos de fibroblastos. Metodología: Los datos de expresión génica de 12 muestras de pterigión primario, 12 de células adiposas y 63 de otros tipos de fibroblastos con la misma plataforma fueron obtenidos de la base de datos Gene Expression Omnibus (GEO). El promedio de expresión para cada gen fue calculado para cada tipo de céIula. Los genes diferencialmente y los similarmente expresados se sometieron a análisis de sobrerrepresentación para obtener vías de señalización, interacciones proteicas y términos funcionales asociados. Resultados: De los 16,511 genes analizados se obtuvieron 921 diferencialmente expresados y 1,207 similarmente expresados. Del análisis de sobrerrepresentación de los genes diferencialmente expresados se encontraron 460 genes asociados $(p<0.05)$ a la proteína SREBP1, mientras que en los genes similarmente expresados se encontraron 615 genes asociados a la misma proteína. Los genes HMGCR, ACOX1 y LRP1 mostraron expresión significativamente disminuida $(p<0.05)$ en fibroblastos de pterigión en comparación con adipocitos y otros tipos de fibroblastos. La expresión del gen HMGCS fue significativamente mayor $(p<0.05)$ en fibroblastos de pterigión que en adipocitos y menor que en otro tipo de fibroblastos. Otros genes, incluidos LPL, ACAT1, LSS, LDLR y LCAT mostraron diferencia de expresión entre los tres tipos celulares. Conclusión: La expresión desregulada de genes asociados al metabolismo de lípidos y colesterol en fibroblastos de pterigión está relacionada con la proliferación, sugiriendo su estudio posterior como posibles blancos terapéuticos.

Palabras clave: Pterigión. Adipocitos. Microarreglos. Colesterol. Lípidos. Fibroblastos.

\section{Abstract}

Purpose: To compare the gene expression associated with lipid and cholesterol metabolism in pterygium fibroblasts, adipocytes and other types of fibroblasts. Methodology: Gene expression data from 12 samples of primary pterygium, 12 from

Correspondencia:

*Judith Zavala

Av. Morones Prieto, 3000

Col. Los Doctores

Fecha de recepción: 23-01-2018

Fecha de aceptación: 05-07-2018

C.P. 64710 , Monterrey, N.L., México

DOI: 10.24875/RMO.M18000053
Disponible en internet: 02-01-2019 Rev Mex Oftalmol. 2019;93(1):7-13 www.rmo.com.mx 0187-4519/@ 2018 Sociedad Mexicana de Oftalmología. Publicado por Permanyer México. Este es un artículo Open Access bajo la licencia CC BY-NC-ND (http://creativecommons.org/licenses/by-nc-nd/4.0/). 
adipose cells and 63 from other types of fibroblasts with the same platform were obtained from the gene expression omnibus database. The mean expression for each gene was calculated for each cell type. Differentially and similarly expressed genes were subjected to overrepresentation analysis to obtain signaling pathways, protein interactions, and associated functional terms. Results: Of the 16,511 genes analyzed, 921 differentially and 1,207 similarly expressed were found. From the overrepresentation analysis of differentially expressed genes, 460 genes were found associated $(p<0.05)$ to the SREBP1 protein, while in the similarly expressed genes 615 were found associated to the same protein. The HMGCR, ACOX1 and LRP1 genes showed significantly decreased expression $(p<0.05)$ in pterygium fibroblasts compared to adipocytes and other types of fibroblasts. Expression of the HMGCS gene was significantly higher $(p<0.05)$ in pterygium fibroblasts than in adipocytes and lower than in other fibroblast types. Other genes, including LPL, ACAT1, LSS, LDLR and LCAT showed a differential expression between the three cell types. Conclusion: Deregulated expression of genes associated with lipid and cholesterol metabolism in pterygium fibroblasts is related to proliferation, suggesting further study as potential therapeutic targets.

Key words: Pterygium. Adipocytes. Microarrays. Cholesterol. Lipid. Fibroblast.

\section{Introducción}

El pterigión es un crecimiento celular anormal en la conjuntiva que posee características tumorales, entre las que se destacan crecimiento descontrolado, invasión y migración. Su aparición se asocia a la exposición solar prolongada. Tiene una incidencia de hasta el $10 \%$ en poblaciones cercanas al ecuador. Es de naturaleza benigna; sin embargo, su crecimiento y migración hacia la región central del ojo puede llegar a interferir con el campo visual, además de causar irritación, inflamación e inducir astigmatismo'.

Aunque no se conocen con precisión los mecanismos que subyacen la patogénesis del pterigión, su desarrollo se asocia a la exposición a los rayos ultravioleta (UV) por la luz solar. Una variedad de factores se ha relacionado con la patogénesis del pterigión, incluyendo factores epigenéticos, mediadores de inflamación, factores de crecimiento, moduladores de la matriz extracelular, factores angiogénicos y linfangiogénicos, mecanismos inmunológicos y alteraciones en el metabolismo del colesterol ${ }^{2}$.

El único tratamiento disponible para la remoción del pterigión es la cirugía, con la desventaja de la recurrencia. Las técnicas quirúrgicas más sofisticadas utilizan autoinjertos conjuntivales o de membrana amniótica para recubrir el área conjuntival de donde se ha removido el pterigión, en búsqueda de mejores resultados estéticos y una reducción de la reincidencia. El uso posquirúrgico de antimetabolitos, como la mitomicina- $C$ y la beta-radioterapia, también son utilizados como adyuvantes en la prevención de la reincidencia ${ }^{3}$.

Las investigaciones sobre la patogénesis del pterigión con el uso de modelos in vitro ha proporcionado información sobre los mecanismos moleculares subyacentes y con ello posibles blancos terapéuticos. Se ha demostrado que en pterigiones humanos, el metabolismo de colesterol se encuentra acelerado y que, cuando se aplican agentes antiproliferativos al pterigión, el metabolismo de colesterol disminuye ${ }^{4}$. Similarmente, se ha encontrado que los fibroblastos de pterigión tienen aumentado el proceso de esterificación del colesterol y esto conlleva un aumento en su tasa de proliferación ${ }^{5}$. Dado que el tejido adiposo es el principal sitio de almacenamiento y metabolismo de lípidos y colesterol, el análisis de vías en común entre este tejido y el pterigión brindaría más información sobre su patogénesis y posibles blancos terapéuticos. Además, la comparación con otro tipo de fibroblastos proporcionaría información sobre las características específicas de los fibroblastos de pterigión.

\section{Propósito}

El objetivo de esta investigación ha sido comparar la expresión de genes asociados al metabolismo de lípidos y colesterol entre fibroblastos de pterigión, adipocitos y otros tipos de fibroblastos e identificar las vías de señalización asociadas.

\section{Metodología}

Los datos sobre el patrón de expresión génica de 8 muestras de pterigión primario (GSE2513, sin usar conjuntiva), 12 de células adiposas (GSE39117, específicamente las T1 pre-LPS) y 63 de otros tipos de fibroblastos de diferentes tejidos del organismo (GSE63626, que contiene 3 de vaso sanguíneo, 4 de pecho, 8 de colon, 6 de duodeno, 6 de esófago, 3 de vesícula biliar, 6 de íleon, 5 de hígado, 3 de pulmón, 7 de glándula mamaria, 3 de próstata, 6 de estómago, y 3 de útero). Todos los datos fueron ensayados con la misma plataforma (Affymetrix Human Genome U133) y fueron obtenidos de la base de datos Gene 
Expression Omnibus (GEO) del National Center for Biotechnology Information (NCBI). Los datos fueron normalizados transformándolos a distribución uniforme entre 0 y 1 antes del análisis. Cero indica nula o muy baja expresión y 1 indica la máxima expresión.

Los datos de expresión génica fueron analizados en Excel. Las regiones de intersección entre los estudios de expresión se obtuvieron por la función BUSCARV, creando una matriz con los mismos genes analizados en ambos tejidos junto con su valor de expresión para cada muestra. Posteriormente, los datos fueron normalizados mediante la función de Excel JERARQUIA. EQV, para asignar la misma jerarquía a los valores utilizados. El promedio de expresión para cada gen fue calculado para células adiposas, fibroblastos de pterigión y otros tipos de fibroblastos. Se calculó la diferencia de expresión, establecida como la resta del promedio de expresión de fibroblastos de pterigión y células adiposas para cada gen y luego se comparó con el promedio de expresión de los fibroblastos de otros tipos.

Se realizó el análisis estadístico de la diferencia de expresión de cada gen con la prueba t de student con los valores normalizados de los diferentes tipos celulares. La diferencia de expresión fue analizada para la determinación del intervalo de diferencia de expresión y valor de prueba t de student en los que existe mayor relación. El intervalo de diferencia de expresión fue establecido usando una diferencia absoluta mayor a 0.4 y una $p<1 \times 10^{-7}$. El intervalo de similitud de expresión fue acotado con una $p>0.5$ y una diferencia $a b-$ soluta en el nivel de expresión $<0.05$.

El análisis de sobrerrepresentación de los genes similarmente y diferencialmente expresados entre fibroblastos de pterigión y células adiposas se hizo mediante la herramienta Gene Functional Classification Tool de DAVID Bioinformatics Resources ${ }^{6,7}$ para obtener los términos de ontología, vías de señalización e interacción proteica asociados. Los genes representativos de las vías del metabolismo de lípidos y colesterol fueron buscados en la matriz de genes en los diferentes tipos de células para comparar su nivel de expresión.

\section{Resultados}

\section{Genes diferencialmente expresados entre adipocitos y fibroblastos de pterigión}

De los 16,511 genes analizados se obtuvieron 921 con un valor $p<1 \times 10^{-7}$ y diferencia absoluta $>0.4$. El análisis de sobrerrepresentación con la herramienta DAVID proporcionó información sobre los términos asociados. Los términos con mayor cantidad de genes asociados representaron aquellos de procesos constitutivos: factores de transcripción, ciclo celular, membrana celular, etcétera (datos no mostrados). Se registraron aquellos términos asociados con un valor $p<0.05$ específicos del metabolismo de lípidos (Tabla 1). No se encontraron vías metabólicas de colesterol y lípidos asociadas significativamente a los genes diferencialmente expresados. Las vías metabólicas que presentaron asociación significativa fueron: vías de cáncer (48 genes), PI3K-Akt (31 genes), proteoglicanos en cáncer (28 genes) y vía de las MAPK (26 genes).

\section{Genes similarmente expresados entre adipocitos y fibroblastos de pterigión}

Se obtuvieron 1,207 genes similarmente expresados ( $p>0.5$ y diferencia absoluta $<0.05$ ). Al realizar el análisis de sobrerrepresentación se encontraron los términos SREBP1 y unión de lípidos relacionados al metabolismo de lípidos (Tabla 2).

\section{Expresión de genes asociados al metabolismo de lípidos y colesterol en adipocitos, fibroblastos de pterigión y otros tipos de fibroblastos}

Se analizó dentro de la matriz de datos los niveles de expresión de los genes ACOX1, HMGCR, HMGCS y $L R P 1$, específicos del metabolismo de lípidos. Se observó que los cuatro genes presentan un mayor nivel de expresión $(p<0.05)$ en otros tipos de fibroblastos en comparación con fibroblastos de pterigión. El gen HMGCS mostró mayor nivel de expresión en fibroblastos de pterigión en comparación con adipocitos, con un valor $p<0.05$. Los fibroblastos de otros tipos mostraron mayor expresión de este gen en comparación con adipocitos y fibroblastos de pterigión. Los genes ACOX1 y LRP1 no mostraron diferencia significativa en el nivel de expresión entre adipocitos y otros tipos de fibroblastos ( $p>0.05$ ) (Fig. 1).

Se compararon, además, los promedios de los niveles de expresión de genes adicionales relacionados al metabolismo de lípidos entre cada tipo celular, generando un mapa de calor (Fig. 2). En general, se observó que la expresión de genes asociados al metabolismo de lípidos y colesterol tiene mayor similitud entre adipocitos y otro tipo de fibroblastos. Los genes con mayor diferencia en el nivel de expresión en 
Tabla 1. Términos asociados $(p<0.05)$ a los genes diferencialmente expresados entre adipocitos y fibroblastos de pterigión obtenidos mediante el análisis de sobrerrepresentación con la herramienta DAVID

\begin{tabular}{|c|c|c|c|}
\hline Categoría & Término & $\begin{array}{l}\text { Número de genes } \\
\text { asociados }\end{array}$ & Ejemplos de genes asociados \\
\hline Interacciones proteicas (UCSC_TFBS) & SREBP1 & 460 & $\begin{array}{l}\text { Stard5, LPL, FADS3, LYPLA2, SREBF1, LRP1, LRP5, } \\
\text { NEDD4 }\end{array}$ \\
\hline \multirow[t]{3}{*}{ Categoría funcional (UP_Keywords) } & Lipoproteínas & 46 & $A K A P 7, \angle R P 1, A P O C 1, C P M, L P L, L D L R A P 1$ \\
\hline & $\begin{array}{l}\text { Metabolismo de } \\
\text { lípidos }\end{array}$ & 26 & $\begin{array}{l}\text { NPC1, ACADL, ACOX1, ACSM5, CROT, CPT1A, } \\
\text { EHHADH, FADS3, LPL, LDLRAP1, LYPLA2, MVK, } \\
\text { SREBF1 }\end{array}$ \\
\hline & $\begin{array}{l}\text { Metabolismo de } \\
\text { ácidos grasos }\end{array}$ & 10 & $\begin{array}{l}\text { ACADL, ACOX1, ACSM5, CROT, CPT1A, EHHADH, } \\
\text { FADS3, LYPLA2, PECR, PTGES }\end{array}$ \\
\hline
\end{tabular}

Tabla 2. Términos asociados $(p<0.05)$ a los genes similarmente expresados entre adipocitos y fibroblastos de pterigión obtenidos mediante el análisis de sobrerrepresentación con la herramienta DAVID

\begin{tabular}{|l|l|c|l|}
\hline Categoría & Término & Número de genes asociados & Ejemplos de genes asociados \\
\hline $\begin{array}{l}\text { Interacciones proteicas (UCSC_TFBS) } \\
\text { Categoría funcional (UP_Keywords) }\end{array}$ & SREBP1 & 615 & $\begin{array}{l}\text { ELOVL4, LRP8, CRAT, CPT1A, CPT2, } \\
\text { ECH1, FFAR2, LDAH de lípidos }\end{array}$ \\
\hline Unión
\end{tabular}

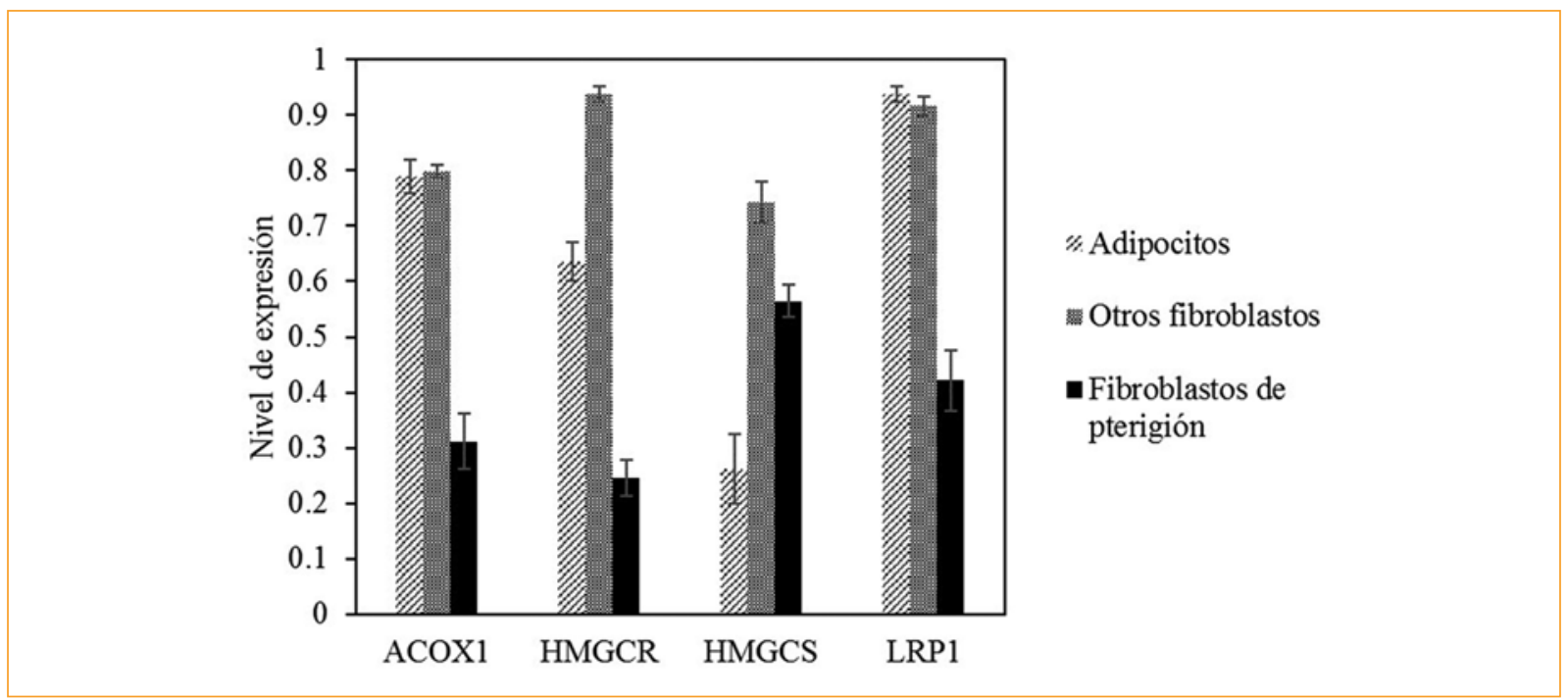

Figura 1. Comparación de los niveles de expresión de los genes ACOX1, HMGCR, HMGCS y LRP1 entre adipocitos, fibroblastos de pterigión y otros tipos de fibroblastos.

fibroblastos de pterigión con respecto a los adipocitos y otros fibroblastos fueron FADS2, FADS3, HMGCR, LPL y APOC1. Los genes LDLRAD4, ACOT1, ACOX1, $\angle R P 1$ y $A P O E$ no mostraron diferencia significativa en su nivel de expresión entre adipocitos y otros fibroblastos $(p>0.05)$.

\section{Discusión}

El análisis de sobrerrepresentación de los genes con expresión similar y diferente entre adipocitos y fibroblastos de pterigión mostró una gran cantidad de genes asociados a procesos constitutivos: factores de 


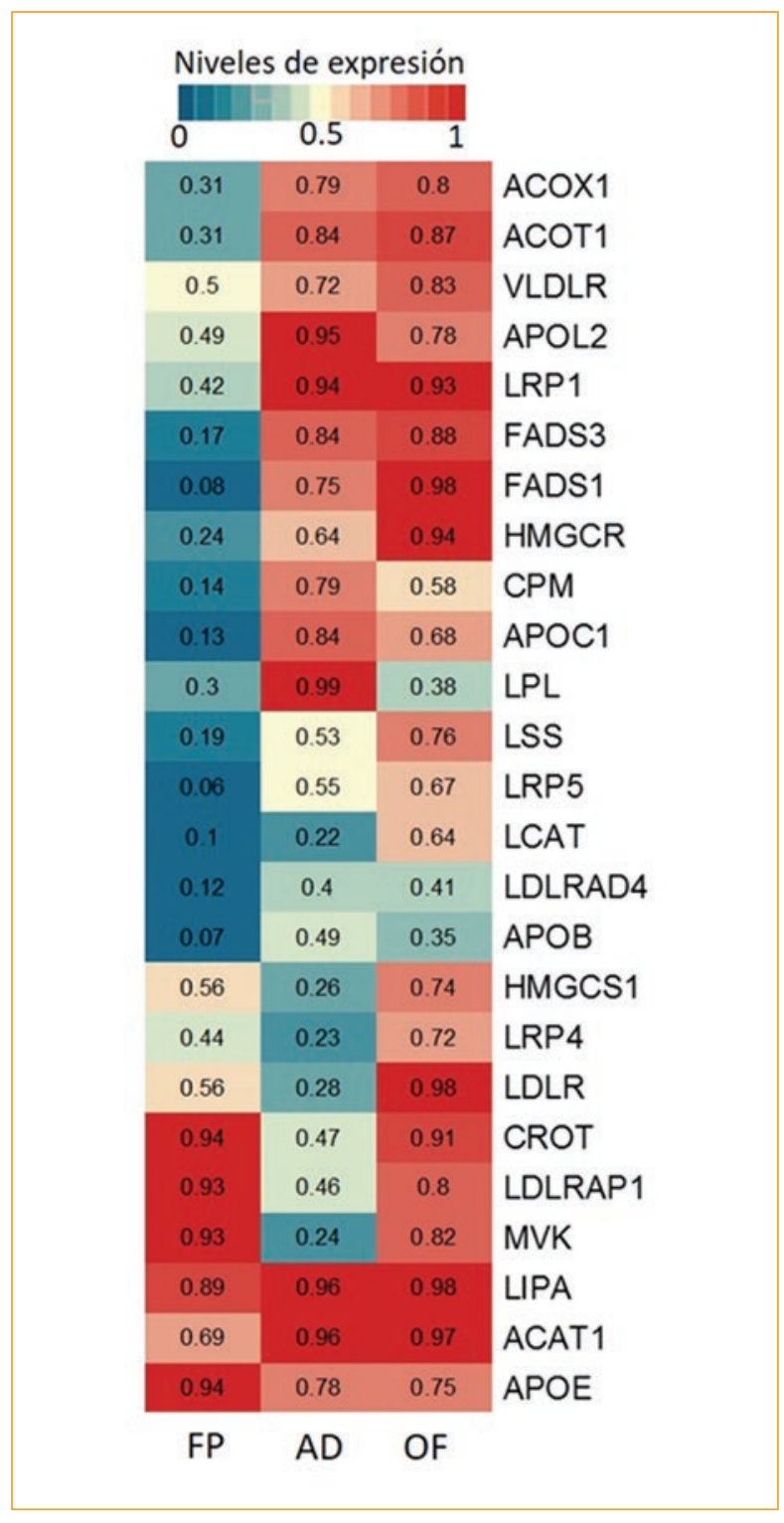

Figura 2. Mapa de comparación del nivel de expresión de genes asociados al metabolismo de lípidos y colesterol.

AD: adipocitos; FP: fibroblastos de pterigión; OF: otros fibroblastos.

transcripción, ciclo celular, membrana celular, etcétera. Al realizar la búsqueda enfocada a colesterol y metabolismo de lípidos, se encontraron términos con asociación significativa con una cuenta mucho menor de genes. De los genes diferencialmente expresados se obtuvieron más términos con asociación significativa al metabolismo de lípidos que en los genes similarmente expresados. El principal término asociado tanto a los genes similarmente como diferencialmente expresados entre fibroblastos de pterigión y adipocitos fue SREBP1.
Este gen codifica para el activador transcripcional requerido para la homeostasia de los lípidos, regulando la transcripción del receptor de lipoproteínas de baja densidad (LDL) y de la síntesis de ácidos grasos y colesterol. Tong, et al. ${ }^{8}$ reportaron que la expresión de SREBP1 en pterigión es mayor al observado en conjuntiva sana. En nuestro análisis, el gen SREBP1 estuvo significativamente aumentado en fibroblastos de pterigión con respecto a lo observado en adipocitos, pero con igual expresión a otro tipo de fibroblastos.

Del análisis comparativo del nivel de expresión de genes asociados al metabolismo de lípidos y colesterol entre fibroblastos de pterigión, adipocitos y otros fibroblastos, se encontraron cuatro genes fundamentales desregulados: ACOX1, HMGCR, HMGCS y LRP1. De estos, solo HMGCS mostró mayor expresión en fibroblastos de pterigión en comparación con adipocitos. En un estudio previo, Peiretti, et al. ${ }^{9}$ demostraron que la $H M G C R$, enzima limitante en la vía de la síntesis de colesterol, se encuentra sobreexpresada en pterigión comparada con pingüécula y conjuntiva sana. En nuestro análisis, el gen HMGCR tuvo menor nivel de expresión en fibroblastos de pterigión en comparación con adipocitos y otros fibroblastos.

Los genes ACOX1, HMGR y LRP1 tuvieron un nivel de expresión promedio menor en fibroblastos de pterigión comparado con adipocitos. La expresión de ACOX1 y LRP1 no tuvo diferencia significativa entre adipocitos y otros fibroblastos. La enzima ACOX1 es la primera enzima en la vía de la beta-oxidación de los ácidos grasos, su disminución causa adrenoleucodistrofia, una enfermedad en donde hay acumulación de ácidos grasos de cadena muy larga ${ }^{10}$. HMGCR es la enzima limitante en la biosíntesis del colesterol y su expresión es directamente proporcional con los niveles séricos del mismo ${ }^{11}$. Se ha demostrado que la inactivación en ratones de $L R P 1$, el gen productor del receptor 1 de lipoproteínas de baja densidad, conlleva a dislipidemia y aterosclerosis ${ }^{12}$.

El gen HMGCS1 mostró orden de nivel de expresión mayor a menor en otros fibroblastos > fibroblastos de pterigión > adipocitos. La diferencia en los niveles de expresión fue significativa. Este gen codifica para la enzima HMGCS1, la cual produce HMG-CoA en el paso crítico en la vía de la biosíntesis del colesterol. Se ha demostrado que la regulación aumentada de esta enzima conlleva a una síntesis elevada de lípidos y aumento de peso ${ }^{13}$. Los genes de las enzimas MVK y LSS, que también participan en la vía de la síntesis de colesterol, se encontraron con diferente expresión en los tres tipos celulares. El gen MVK tuvo mayor 
expresión en fibroblastos de pterigión, otros fibroblastos y adipocitos. Mientras que el gen LSS se encontró con menor expresión en comparación con adipocitos y otros fibroblastos. En conjunto, la desregulación de la expresión de genes de enzimas asociadas a la síntesis de colesterol explica la sobreproducción reportada por Peiretti4.

Dentro de los genes analizados, también se encontraron diferencias de expresión en aquellos que codifican para enzimas del metabolismo de lipoproteínas. Los genes $A P O B, A P O C 1$ y APOL2 se encontraron con expresión significativamente disminuida en fibroblastos de pterigión con respecto a adipocitos y otros fibroblastos, mientras que el gen $A P O E$ se encontró sobreexpresado. APOB es el principal componente proteico de los quilomicrones (apoB-48), LDL y lipoproteínas de muy baja densidad (VLDL) (apoB-100). Las mutaciones de este gen conllevan a niveles desregulados de LDL en sangre e hipercolesterolemia ${ }^{14}$. La desregulación de la expresión de los genes $A P O C 1$ y $A P O L 1$ se relaciona también con el desarrollo de trigliceridemia $^{15,16}$. Se conoce que APOE media el metabolismo del colesterol y diferentes isoformas se asocian a hiperlipidemia e hipercolesterolemia ${ }^{17}$. LRP1 es el gen productor del receptor 1 de las LDL. Este receptor se involucra en la señalización intracelular y endocitosis de las lipoproteínas. Se ha demostrado que la inactivación de este gen en ratones conlleva a dislipidemia y aterosclerosis ${ }^{12}$. El análisis mostró expresión de este gen en fibroblastos de pterigión disminuida significativamente en comparación con adipocitos y otros fibroblastos, lo cual se correlaciona con el aumento en el metabolismo de colesterol ya descrito.

Los niveles de expresión de los genes $L P L, L C A T$, $F A D S 1$ y FADS3 se encontraron significativamente disminuidos en fibroblastos de pterigión respecto a los adipocitos y otros fibroblastos. Estos genes codifican para enzimas que participan en la homeostasis del colesterol y ácidos grasos. La lipoproteinlipasa (LPL) hidroliza a los triglicéridos produciendo ácidos grasos libres y glicerol. Se ha demostrado que la deficiencia de esta enzima conlleva a hiperlipoproteinemia e hipertrigliceridemia $^{18}$. La lecitina colesterolaciltransferasa (LCAT) convierte el colesterol libre a esteres de colesterol, la forma hidrofóbica del colesterol que forma parte de las lipoproteínas. La deficiencia de LCAT está asociada al aumento de los niveles de lipoproteínas de alta densidad (HDL) unido a colesterol e hipertrigliceridemia $^{19}$. Las enzimas FADS1 y FADS3 desaturan los ácidos grasos produciendo ácidos grasos poliinsaturados, que son esenciales en el ser humano, su desregulación ha sido asociada a la hiperlipidemia ${ }^{20-22}$.

El gen ACOT1 se encontró con expresión disminuida en fibroblastos de pterigión. Este gen codifica para la enzima acil-CoA tioesterasa, que regula los niveles intracelulares de ésteres-CoA, coenzima $A$ y ácidos grasos libres. Se ha sugerido una relación funcional entre los niveles de esta enzima y la oxidación de ácidos grasos y que la regulación de ACOT1 es adaptativa como protección de la sobreproducción de ácidos gra$\operatorname{sos}^{23}$. La expresión de ACOT1 fue igual entre adipocitos y otros fibroblastos.

En general, la desregulación de los genes analizados provee un panorama más amplio de los mecanismos que subyacen al aumento de colesterol encontrado en el pterigión, que a su vez se relaciona con el aumento en la proliferación celular característica de esta patología.

\section{Conclusiones}

El pterigión es un crecimiento anormal en la conjuntiva que solo puede ser tratado con remoción quirúrgica. Aunque este tratamiento ha ido mejorando hasta el desarrollo de injertos autoconjuntivales y de membrana amniótica, aún no se ha logrado prevenir por completo la recurrencia. Este problema de salud es específicamente importante en regiones cercanas al ecuador, en donde la incidencia es mayor por la exposición a los rayos UV solares.

En el estudio de la patogénesis, se ha reportado que el colesterol es una de las vías desreguladas en el tejido de pterigión, lo cual contribuye al mecanismo de proliferación desregulada. Esto provee herramientas para la identificación de blancos terapéuticos que puedan ser abordados farmacológicamente para la disminución, eliminación o prevención de la recurrencia del pterigión.

En este sentido, se han reportado análisis del patrón de expresión génica por microarreglos y análisis por proteómica del pterigión. Sin embargo, la cantidad de información obtenida de estos análisis es muy vasta y la identificación de vías importantes puede llevar mucho tiempo. En estos análisis, la expresión génica del pterigión es comparada con la de conjuntiva sana. En este análisis se corroboró la desregulación del gen HMGCR previamente reportada en pterigión y se comparó por primera vez su nivel de expresión con adipocitos y otros fibroblastos. El análisis adicional de genes asociados al metabolismo del colesterol y de lipoproteínas demostró que los 
fibroblastos de pterigión tienen diferente patrón de expresión que otros tipos de fibroblastos y adipocitos, y que estos dos últimos tienen similar patrón de expresión de este tipo de genes. A la fecha, no se han encontrado reportes similares. El conocimiento de las vías lipídicas desreguladas en el pterigión proporciona herramientas para el estudio de su patogénesis y para el análisis de posibles blancos terapéuticos farmacológicos.

\section{Responsabilidades éticas}

Protección de personas y animales. Los autores declaran que para esta investigación no se han realizado experimentos en seres humanos ni en animales.

Confidencialidad de los datos. Los autores declaran que en este artículo no aparecen datos de pacientes.

Derecho a la privacidad y consentimiento informado. Los autores declaran que en este artículo no aparecen datos de pacientes.

\section{Conflicto de intereses}

Los autores declaran que no existe conflicto de intereses en el desarrollo de este trabajo de investigación.

\section{Bibliografía}

1. Mohammed I. Treatment of pterygium. Ann Afr Med. 2011;10:197-203.

2. Cardenas-Cantu E, Zavala J, Valenzuela J, Valdez-Garcia JE. Molecular Basis of Pterygium Development. Semin Ophthalmol. 2016;31:567-83.

3. Hacioglu D, Erdol H. Developments and current approaches in the treatment of pterygium. Int Ophthalmol. 2017;37:1073-81.

4. Peiretti E, Dessi S, Mulas MF, Abete C, Galantuomo MS, Fossarello M. Fibroblasts isolated from human pterygia exhibit altered lipid metabolism characteristics. Exp Eye Res. 2006;83:536-42.
5. Galantuomo M, Mulas MF, Baire P, Abete C, Peiretti E, Dessì S, et al. Proliferative Activity and Cholesterol Ester Metabolism in Primary Culture of Human Pterygium Fibroblasts. Invest Ophthalmol Vis Sci. 2005;46:960.

6. Huang DW, Sherman BT, Lempicki RA. Bioinformatics enrichment tools: paths toward the comprehensive functional analysis of large gene lists. Nucleic Acids Res. 2009;37:1-13.

7. Haung DW, Sherman BT, Lempicli RA. Systematic and integrative analysis of large gene lists using DAVID bioinformatic resources. Nat Protoc. 2009;4:44-57.

8. Tong L, Chew J, Yang H, Ang LPK, Tan DTH, Beuerman RW. Distinct gene subsets in pterygia formation and recurrence: dissecting complex biological phenomenon using genome wide expression data. BMC Med Genomics. 2009;2:14.

9. Peiretti E, Dessi S, Putzolu M, Fossarello M. Hyperexpression of low-density lipoprotein receptors and hydroxy-methylglutaryl-coenzyme A-reductase in human pinguecula and primary pterygium. Invest Ophthalmol Vis Sci. 2004;45:3982-5.

10. Shimozawa N. Molecular and clinical aspects of peroxisomal diseases. J Inherit Metab Dis. 2007;30:193-7.

11. Arnaud C, Veillard NR, Mach F. Cholesterol-independent effects of statins in inflammation, immunomodulation and atherosclerosis. Curr Drug Targets Cardiovasc Haematol Disord. 2005;5: 127-34.

12. Gordts PL, Reekmans S, Lauwers A, Van Dongen A, Verbeek L, Roebroek AJ. Inactivation of the LRP1 intracellular NPxYxxL motif in LDLR-deficient mice enhances postprandial dyslipidemia and atherosclerosis. Arterioscler Thromb Vasc Biol. 2009;29:1258-64.

13. Raeder MB, Ferno J, Glambek M, Stansberg C, Steen VM. Antidepressant drugs activate SREBP and up-regulate cholesterol and fatty acid biosynthesis in human glial cells. Neurosci Lett. 2006;395:185-90.

14. Farese RV Jr, Linton MF, Young SG. Apolipoprotein B gene mutations affecting cholesterol levels. J Intern Med. 1992;231:643-52.

15. Berbée JFP, van der Hoogt CC, Sundararaman D, Havekes LM, Rensen, PCN. Severe hypertriglyceridemia in human APOC1 transgenic mice is caused by apoC-I-induced inhibition of LPL. J Lipid Res. 2005;46:297-306.

16. Duchateau PN, Movsesyan I, Yamashita S, Sakai N, Hirano KI, Schoenhaus SA, et al. Plasma apolipoprotein $L$ concentrations correlate with plasma triglycerides and cholesterol levels in normolipidemic, hyperlipidemic, and diabetic subjects. J Lipid Res. 2000;41:1231-6.

17. Mahley RW, Rall SC Jr. Apolipoprotein E: far more than a lipid transport protein. Annu Rev Genomics Hum Genet. 2000;1:507-37.

18. Okubo M, Horinishi A, Saito M, Ebara T, Endo Y, Kaku K, et al. A novel complex deletion-insertion mutation mediated by Alu repetitive elements leads to lipoprotein lipase deficiency. Mol Genet Metab. 2007;92:229-33.

19. Ossoli A, Simonelli S, Vitali C, Franceschini G, Calabresi L. Role of LCAT in Atherosclerosis. J Atheroscler Thromb. 2016;23:119-27.

20. Hastings N, Agaba M, Tocher DR, Leaver MJ, Dick JR, Sargent JR. A vertebrate fatty acid desaturase with $\Delta 5$ and $\Delta 6$ activities 2001;25:14304-9.

21. Plaisier CL, Horvath S, Huertas-Vazquez A, Cruz-Bautista I, Herrera MF, Tusie-Luna T. A systems genetics approach implicates USF1, FADS3, and other causal candidate genes for familial combined hyperlipidemia. PLoS Genet. 2009;5:e1000642.

22. Huang MC, Chang WT, Chang HY, Chung HF, Chen FP, Huang YF, et al. FADS Gene Polymorphisms, Fatty Acid Desaturase Activities, and HDL-C in Type 2 Diabetes. Int J Environ Res Public Health. 2017;14:E572.

23. Fujita M, Momose A, Ohtomo T, Nishinosono A, Tanonaka K, Toyoda H, et al. Upregulation of fatty acyl-CoA thioesterases in the heart and skeletal muscle of rats fed a high-fat diet. Biol Pharm Bull. 2011;34:87-91. 